\title{
Heat transfer characteristics on MHD Powell-Eyring fluid flow across a shrinking wedge with non-uniform heat source/sink
}

\author{
K. Anantha Kumar ${ }^{1}$, B. Ramadevi ${ }^{1}$, V. Sugunamma ${ }^{1, *}$ and J. V. Ramana Reddy ${ }^{2}$ \\ ${ }^{1}$ Department of Mathematics, Sri Venkateswara University, \\ Tirupati 517502, Andhra Pradesh, INDIA \\ Phone: +91 9491152154 \\ *Email: vsugunar@gmail.com \\ ${ }^{2}$ Department of Humanities and Sciences \\ Krishna Chaitanya Institute of Technology and Sciences, \\ Markapur 523316, Andhra Pradesh, INDIA
}

\begin{abstract}
This report presents the flow and heat transfer characteristics on magnetohydrodynamic nonNewtonian fluid across a wedge near the stagnation point. The fluid flow is time independent and laminar. The radiation and irregular heat sink/source effects are deemed. The system of nonlinear ODEs is attained from PDEs by choosing the proper similarity transformations. Further, the well-known shooting and Runge-Kutta methods are utilized to acquire the problem's solution subject to assumed boundary conditions. Figures are outlined to emphasize the impact of several parameters on the fields of velocity and temperature. Further, the rate of heat transfer and friction factor are also anticipated and portrayed with the assistance of table. Results indicate that the curves of velocity diminish with shrinking parameter, magnetic field parameter and material fluid parameter. Also the non-uniform heat source/sink parameters play a crucial role in the heat transfer performance.
\end{abstract}

Keywords: MHD; heat transfer; Powell-Eyring fluid; thermal radiation; shrinking wedge; non-uniform heat source/sink.

\section{INTRODUCTION}

Present researchers enthusiastic on examining the thermal transport attributes in boundary layer flows past wedge shaped geometries due to its event in distinct applications scientifically and industrially such as heat exchangers, extraction of crude oils, thermal insulation, plasma studies and boundary layer control in aerofoil, etc. Those liquids which don't satisfying the Newton's law of viscosity are labeled as non-Newtonian. Glue, shampoo, banana juice, starch, honey, blood are some illustrations of non-Newtonian liquids. PowellEyring liquid is one of the special kinds of these liquids. Chamkha et al. [1] considered a problem to study the impact of radiation on free convective non-Newtonian liquid motion across a permeable wedge. The magneto hydrodynamic free convective motion of shear thinning liquid across a stretchable domain was analyzed by Eldaheb and Salem [2]. The features of heat transport on MHD shear thinning viscoelastic liquid due to a wedge were reported by Hsiao [3]. Surati and Timol [4] have been presented a numerical study on 
convective motion of non-Newtonian liquid over a wedge and concluded that the velocity function and non-Newtonian parameters are inversely proportional. The flow and thermal transport features on an electrically conducting pseudo plastic liquid owing to a strained geometry was inspected by Kumar et al. [5]. Postelincu and Pop [6] have given a mathematical model to analyze the Falkner-Skan motion of shear thinning fluid through a permeable stretching wedge. Some notable information about shear thinning liquid flows over a stretched geometry can be view in [7-9]. They get the problem's solution by wellknown R.K. based shooting technique.

The study of magnetohydrodynamics (MHD) contracts with the motion of electrically accompanying fluids. This notion has relevant in numerous practices such as bearings, pumps, magnetic drug treating, accelerators, drift meters, electricity producers, cooling of reactors, plasma analysis and the design of heat exchangers. Motivating by these solicitations, Khan et al. [10] inspected the stimulus of heat production on an electrically conducting nanofluid motion across a wedge and concluded that temperature profile have an inverse relationship with the mass convective parameter. Awaludin et al. [11] and Kumar et al. [12] scrutinized the heat transport features of 2D MHD stratified motion owing to a wedge. The flow attributes on natural convective motion past a shrinking wedge was discussed by Khan and Pop [13]. Recently, researchers [14-15] have been paid their interest to scrutiny the flow, thermal transport features on MHD flows across a stretched sheet. By exploiting the suitable transformations the flow equations are metamorphosed to dimensionless and then tackled by R.K.F-4.

The impacts of varying heat and radiation on convective flows play an immense role in space technology and in many industrial processes involving higher temperatures, such as manufacture of paper plates, cooling of metallic pieces, making of chips and petroleum pumps. Rashidi et al. [16] deemed the behavior of buoyancy and radiation on MHD motion of shear thickening liquid due to stretched sheet. The impact of Brownian moment on Newtonian liquid across a wedge in the attendance of drag force was inspected by Kandaswamy et al. [17]. Hayat et al. [18] considered a problem to inspect the impact of radiation on Eyring-Powell liquid motion across a stretched surface and concluded that the heat function and fluid temperature are proportional to each other. The Falkner-Skan movement of power-law liquid owing to a shrinking wedge with slip effects was deliberated by Mutlag et al. [19].

Pal [20] studied the impact of irregular heat sink/source on unsteady movement of Newtonian liquid over a stretched geometry and establish that positive values of uneven heat constraints magnifies the curves of thermal fields. The Joule and frictional heating effects on electrically conducting bio convective motion over a penetrable wedge can be seen in [21]. Reddy et al. [22] examined the variable heat parameters impact on electrically accompanying nanoliquid across a coagulated sheet. The mass plus thermal features on MHD motion of Williamson fluid across a curved surface was examined by Kumar et al. [23-24]. The shooting and Runge-Kutta explorations are exploited to obtain the problem elucidation. The effect Eckert number on time independent motion of shear thinning nanoliquids due to a needle was examined by Sulochan et al. [25]. Yacob et al. [26] scrutinized the 2D motion over a wedge. Keller-Box numerical scheme is utilized to obtain the solution of the problem. It was found that increasing values of volume fraction of nanofluids and the angle of the wedge enhanced the friction factor. The influence of bouncy forces on MHD Rivlin-Ericksen liquid over a stretched geometry can view in [27-28]. The mass transport features on MHD 
Newtonian liquid across a vertical plate in the attendance of Lorentz force was reported by the authors [29-30]. Suction or blowing impacts on convection flow across a wedge was scrutinized by Yin [31]. A well-known numerical scheme is utilized to get the problem solution. Armstrong and Muthucumaraswamy [32] examined the influence of drag force on free convective motion of Newtonian liquid across a vertical plate. The Laplace transform technique is utilized to get the problem solution.

To the best of our knowledge, no author made an attempt to investigate the flow and heat transfer characteristics of stagnation point flow of Powell-Eyring fluid past a shrinking wedge surface. Hence motivated by the applications of thermal radiation, Lorentz force, variable heat source or sink and non-Newtonian fluids we aimed to a theoretical analysis on the two-dimensional stagnation point flow of Powell-Eyring fluid due to stretching of a wedge surface near the stagnation point. The flow equations are built in view of various physical situations like free convection, variable heat sink/source and thermal radiation. The problem is formulated using the model Khan et al. [10]. The governing equations are highly nonlinear and coupled PDEs. These equations are converted to ODEs by suitable similarity variables. The transformed equations are linearized by shooting and then solved by RungeKutta fifth order method. The graphs and numerical values are presented with the aim of analysing the velocity, temperature, friction factor and local heat transfer rate for the variation in physical parameters.

\section{MATHEMATICAL FORMULATION OF THE PROBLEM}

An incompressible, time-independent magneto hydrodynamic flow of Powell-Eyring liquid across a shrinking wedge is considered. The flow is laminar and time independent. The flow is taken along the $x$-axis and $y$-axis is taken perpendicular to it. Let us assume that the wedge is shrinking with the velocity $u_{w}=a x^{m}$ and $u_{e}=c x^{m}$ is the free stream velocity, where $a, m \& c$ are non-negative quantities and $m$ is the power law index. A varying magnetic force $B=B_{0} x^{m-1 / 2}$ is applied opposite to the flow. The thermal radiation and variable heat sink/source effect is also taken into account. But the frictional heat generated by dissipation is not accounted. It is worth to mention that $\left(u_{w}(x)>0, u_{w}(x)<0\right)$ correspondingly, the flow due to stretching/shrinking wedge. The flow geometry of model is revealed in Figure 1. The expression for stress tensor in the Powell-Eyring model is (see Ref. [10] and [18])

$$
\tau_{i j}=\mu \frac{\partial u_{i}}{\partial x_{j}}+\frac{1}{\beta} \sinh ^{-1}\left(\frac{1}{d} \frac{\partial u_{i}}{\partial x_{j}}\right),
$$

To compute the stress components in Eq. (1), the function is approximated as

$$
\sinh ^{-1}\left(\frac{1}{d} \frac{\partial u_{i}}{\partial x_{j}}\right) \cong \frac{1}{d} \frac{\partial u_{i}}{\partial x_{j}}-\frac{1}{6}\left(\frac{1}{d} \frac{\partial u_{i}}{\partial x_{j}}\right)^{3},\left|\frac{1}{d} \frac{\partial u_{i}}{\partial x_{j}}\right| \leq 1,
$$

Here $\mu$ is the viscosity (dynamic), $(\beta, d)$ are the parameters related to material fluid. 


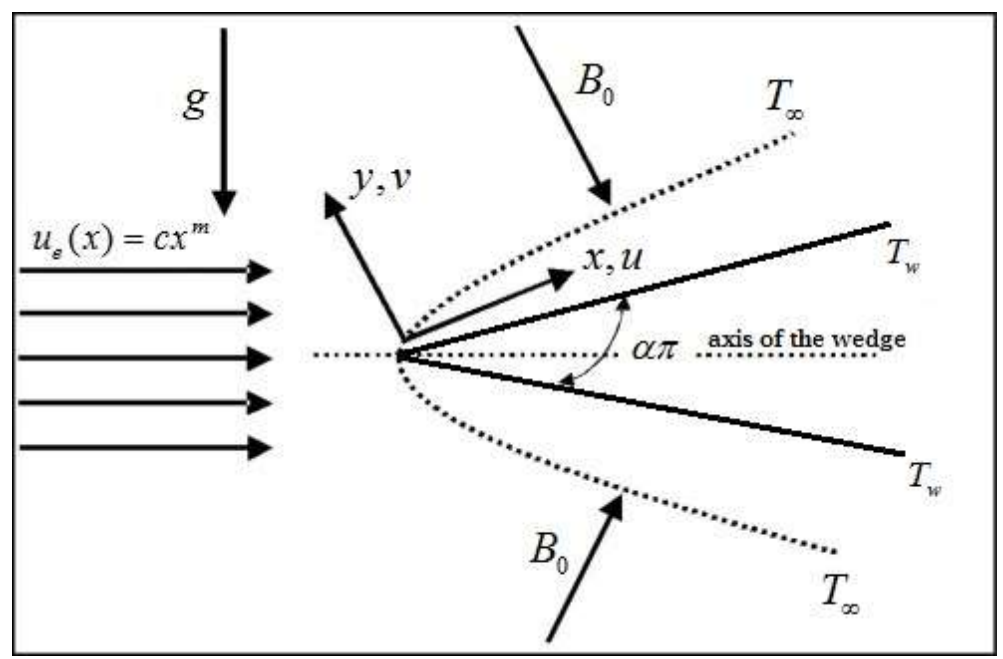

Figure 1: Flow Geometry (see Ref. [10])

In view of the above stated assumptions, the basic equations for momentum and energy for the proposed model as, (see Ref. [10], [14] and [18])

$$
\begin{gathered}
\frac{\partial u}{\partial x}+\frac{\partial v}{\partial y}=0 \\
\frac{\partial u}{\partial x} u+\frac{\partial u}{\partial y} v=u_{e} \frac{d u_{e}}{d x}+\frac{\partial^{2} u}{\partial y^{2}}\left(\left(v+\frac{1}{\rho \beta d}\right)-\frac{1}{2 \rho \beta d^{3}}\left(\frac{\partial u}{\partial y}\right)^{2}\right)-\frac{\sigma B(x)^{2}}{\rho} u+g \beta_{T}\left(T-T_{\infty}\right), \\
\frac{\partial T}{\partial x} u+\frac{\partial T}{\partial y} v=\frac{1}{\rho c_{p}}\left(k \frac{\partial^{2} T}{\partial y^{2}}+Q^{\prime \prime \prime}-\frac{\partial q_{r}}{\partial y}\right)
\end{gathered}
$$

The conditions of the boundary are (see Ref. [10], [14] and [18])

$$
\left.\begin{array}{ll}
u=u_{w}=-u_{e}, v=0, T=T_{w}, & \text { at } y=0, \\
u=u_{e}, T=T_{\infty}, & \text { as } y \rightarrow \infty,
\end{array}\right\}
$$

Here $(u, v)$ are the constituents of velocity along the horizontal and vertical ways of the wedge surface respectively, $v$ is the viscosity (kinematic), $\rho$ is density, $d$ is a constant, $\sigma$ is the fluid's electrical conductivity, $g$ is the gravitational force, heat development constant is $\beta_{T}, T$ is temperature, $T_{w} \& T_{\infty}$ are the near and ambient temperatures of the liquid from the wedge surface correspondingly, $c_{p}$ is the heat capacitance and $k$ is the thermal conductivity.

In Eq. (3), $Q^{\prime \prime \prime}$ taken by (see Ref. [14])

$$
Q^{\prime \prime \prime}=\frac{k u_{e}(x)}{x v}\left(\left(T_{w}-T_{\infty}\right) A^{*} f^{\prime}-\left(T_{\infty}-T\right) B^{*}\right),
$$

Here an enhancement and decrement in $A^{*}, B^{*}$ indicates the internal heat sink/source correspondingly.

The heat flux with linear Roseland approximation is (see Ref. [10]) 


$$
q_{r}=\frac{-4 \sigma^{*}}{3 k^{*}} \frac{\partial T^{4}}{\partial y}
$$

Here $\left(\sigma^{*}, k^{*}\right)$ signify, the Stefan-Boltzmann and mean absorption factors.

Consider the Taylor's series expansion of $T^{4}$ about $T_{\infty}$ is

$$
T^{4} \cong 4 T_{\infty}^{3} T-3 T_{\infty}^{4}
$$

\section{SIMILARITY TRANSFORMATIONS}

Now we alter the Eqs. (3)-(6) into dimensionless form, we define the stream function $\eta$ and the suitable similarity transformation $\xi$ as follows (see Ref. [10], [14] and [18]).

$$
\eta=\sqrt{\frac{2 u_{e} x v}{1+m}} f(\xi), \xi=\sqrt{\frac{(1+m) u_{e}}{2 x v}} y,
$$

The velocity components $u, v$ in $\eta$ as

$$
u=\frac{\partial \eta}{\partial y}=c x^{m} f^{\prime},-v=\frac{\partial \eta}{\partial x}=\sqrt{\frac{2 c v}{1+m}} x^{\frac{m-1}{2}}\left(\frac{m+1}{2} f+\frac{m-1}{2} \xi f^{\prime}\right), \theta=\frac{T-T_{\infty}}{\left(T_{w}-T_{\infty}\right)},
$$

Here $f^{\prime}(\xi)$ and $\theta(\xi)$ indicate the dimensionless velocity and thermal fields correspondingly. In view of Eqs. (7)-(11), the Eqs. (4) and (5) altered as follows, whereas the continuity equation will be automatically satisfied.

$$
\begin{gathered}
\left(1+\varepsilon-\varepsilon \delta \frac{m+1}{2}\left(\frac{d^{2} f}{d \xi^{2}}\right)^{2}\right) \frac{d^{3} f}{d \xi^{3}}+f \frac{d^{2} f}{d \xi^{2}}+\left(\frac{2 m}{m+1}\right)\left(1-\left(\frac{d f}{d \xi}\right)^{2}\right)=\frac{2}{m+1}\left(M \frac{d f}{d \xi}-\Gamma \theta\right), \\
(1+R d) \frac{d^{2} \theta}{d \xi^{2}}+\operatorname{Pr} f \frac{d \theta}{d \xi}+\frac{2}{m+1}\left(A^{*} \frac{d f}{d \xi}+B^{*} \theta\right)=0
\end{gathered}
$$

The corresponding boundary restrictions

$$
\begin{array}{ll}
f=1, \frac{d f}{d \xi}=-\lambda, \theta=1, & \text { at } \xi=0, \\
\frac{d f}{d \xi}=1, \quad \theta=0, & \text { as } \xi \rightarrow \infty
\end{array}
$$

In the above equations $\varepsilon, \delta, M, \Gamma, G r_{x}, \operatorname{Pr}, \operatorname{Re}_{x}, R d, A^{*}, B^{*}$ and $\lambda$ are the material fluid constants, magnetic force parameter, convection parameter, thermal Grashof number, Prandtl number, Reynolds number, radiation parameter, uneven heat sink or source parameters and constant of moving parameter. The expressions for these parameters are as given below.

$$
\left.\begin{array}{l}
\varepsilon=\frac{1}{\mu \beta d}, \delta=\frac{c^{3} x^{3 m-1}}{2 d^{2} v}, \Gamma=\frac{G r_{x}}{\operatorname{Re}_{x}^{2}}, G r_{x}=\frac{g \beta_{T}\left(T_{w}-T_{\infty}\right)}{v^{2}}, \\
\operatorname{Re}_{x}=\frac{u_{e} x}{v}, M=\frac{\sigma B_{0}^{2}}{\rho c}, \operatorname{Pr}=\frac{\mu c_{p}}{k}, R d=\frac{16 \sigma^{*} T_{\infty}^{3}}{3 k k^{*}}, \lambda=\frac{a}{c},
\end{array}\right\}
$$

For engineering and industrial purpose, we calculate the quantities $C_{f}$ and $N u_{x}$. 
The definition of friction factor is (see Ref. [10])

$$
C_{f}=\frac{\tau_{w}}{\rho u_{e}^{2}}
$$

Here $\tau_{w}=\mu\left(\frac{\partial u}{\partial y}\right)_{y=0}$, is shear stress of the wedge surface.

From Eq. (11), Eq. (16) converted as

$$
\operatorname{Re}_{x}^{1 / 2} C_{f}=\left((1+\varepsilon) f^{\prime \prime}(0)-\frac{\varepsilon \delta}{3} f^{\prime \prime 3}(0)\right),
$$

The definition of heat transport rate is (see Ref. [10])

$$
N u_{x}=\frac{x q_{w} k^{-1}}{\left(T_{w}-T_{\infty}\right)}
$$

Here $q_{w}=-k\left(\frac{\partial T}{\partial y}\right)_{y=0}+q_{r}$, is the heat flux.

From Eq. (11), Eq. (18) becomes

$$
\operatorname{Re}_{x}^{-1 / 2} N u_{x}=-(1+R d) \theta^{\prime}(0),
$$

\section{METHOD OF SOLUTION}

The nonlinear, coupled ODEs (12)-(13) and the corresponding restrictions of the boundary (14) have been resolved numerically by R.-K. method. Afore that the nonlinear Eqs. (12)(14) are renewed to linearized by shooting practice. The process is as follows.

First we assume that,

$$
f=y_{1}, f^{\prime}=y_{2}, f^{\prime \prime}=y_{3}, f^{\prime \prime \prime}=y_{3}^{\prime}, \theta=y_{4}, \theta^{\prime}=y_{5}, \theta^{\prime \prime}=y_{5}^{\prime},
$$

Substituting Eqn. (20) in the Eqs. (12)-(14), we get the simultaneous ODEs

$$
\begin{gathered}
y_{1}^{\prime}=y_{2}, \\
y_{2}^{\prime}=y_{3}, \\
y_{3}^{\prime}=\left(\frac{2}{2(1+\varepsilon)-(m+1) \varepsilon \delta y_{3}{ }^{\prime}}\right)\left(\begin{array}{c}
2 m \\
\left.-y_{1} y_{3}-\frac{2 m}{m+1}\left(1-y_{2}^{2}\right)+\frac{2 m}{m+1} y_{2}-\frac{2 m}{m+1} y_{4}\right), \\
y_{4}^{\prime}=y_{5}, \\
y_{5}^{\prime}=\left(\frac{1}{1+R d}\right)\left(-\operatorname{Pr} y_{1} y_{5}-\left(\frac{2}{m+1}\right)\left(A^{*} y_{2}-B^{*} y_{4}\right)\right), \\
y_{1}(0)=1, y_{2}(0)=-\lambda, y_{4}(0)=1, \\
y_{2}(\infty) \rightarrow 1, y_{4}(\infty)=0,
\end{array}\right\}
\end{gathered}
$$




\section{MODEL VALIDATION}

Table 1. Assessment of the values of friction factor $\left(-f^{\prime \prime}(0)\right)$ when $M=0, \varepsilon=0, \Gamma=0$, $\delta=0$ and $\lambda=0$ with the boundary conditions

\begin{tabular}{cccc}
\hline$m$ & {$[26]$} & {$[31]$} & Present study \\
\hline 0.0 & 0.4696 & 0.46960 & 0.46959 \\
0.0909 & 0.6550 & 0.654979 & 0.65496 \\
0.2 & 0.8021 & 0.802125 & 0.80213 \\
0.3 & 0.9277 & 0.92765 & 0.92771 \\
0.5 & 1.0389 & - & 1.03890 \\
1.0 & 1.2326 & 1.232533 & 1.23262 \\
\hline
\end{tabular}

Table 1. Illustrate the contrast of the present results of $-f^{\prime \prime}(0)$ with the available results of Yacob [26] and Yin [31]. We establish an outstanding agreement with the existed consequences under some different conditions. This confirms the validity of our work and the numerical procedure we use in this scrutiny.

\section{RESULTS AND DISCUSSION}

This subdivision focuses on the physical behaviour of the involved parameters on the distributions of velocity and heat functions. The influence of different physical parameters like magnetic parameter, material fluid parameter, non-uniform heat parameters, radiation parameter, Prandtl number and mixed convection parameters on the flow fields, friction factor and rate of thermal transport have been deliberated in detail with the support of Figures. (2)-(11) and Table 2. We have allocated the values for the flow parameters as $M=1.5, \operatorname{Pr}=6.8, \lambda=0.2, \Gamma=0.4, A^{*}=B^{*}=0.2, R d=0.3$ and $\varepsilon=0.2$. For the entire study these values are mutual apart from the altered constraints as revealed in the diagrams and tables. In the entire discussion $f^{\prime}(\xi)$ and $\theta(\xi)$ represent the velocity and heat functions.

Figures 2 and 3 are pinched to see the consequence of $M$ on the scatterings of velocity and temperature respectively. We clinch that a rise in $M$ consequences a climb in temperature but a reduction in velocity. Actually, an upsurge in $M$ generates a Lorentz force in motion, which has proclivity to deliberate the movement of particles. Owing to these force, heat function and its layer thickness enhances but the momentum thickness suppress with $\operatorname{larger} M$. 


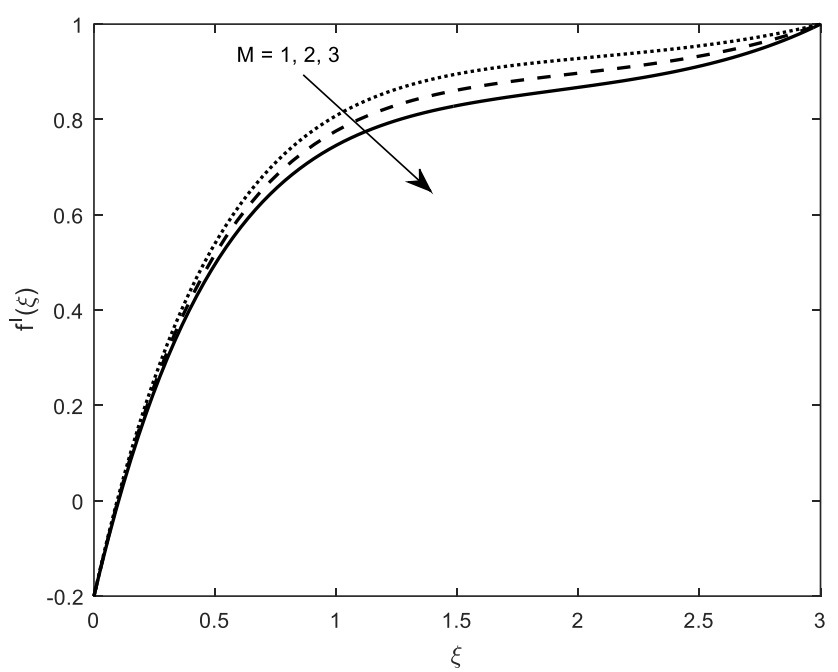

Figure 2. Influence of $M$ on the curves of velocity.

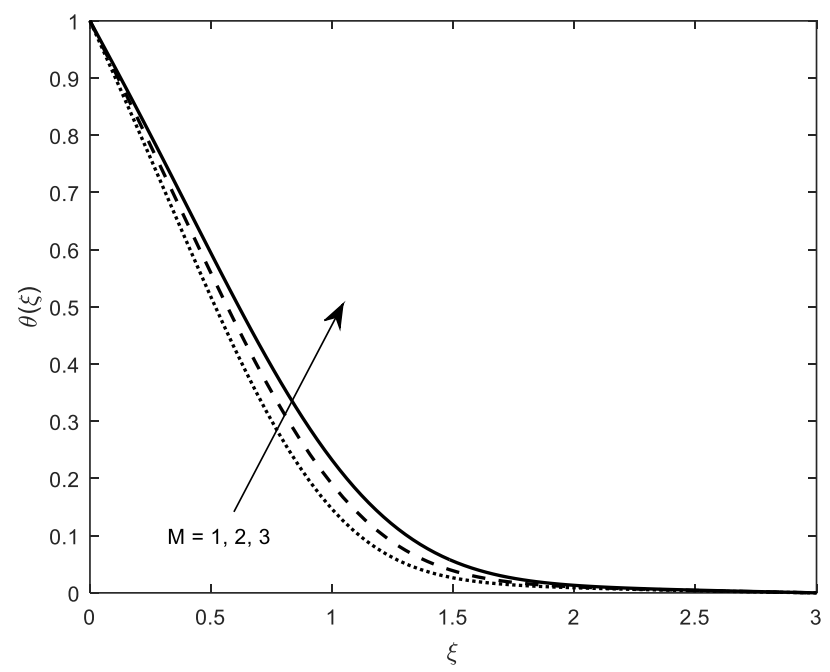

Figure 3. Influence of $M$ on the curves of temperature.

Figures 4 and 5 are constructed to discuss the impression of irregular heat parameters on the curves of $\theta(\xi)$. It is found that increasing values of either of the parameters $A^{*}, B^{*}$ increases the fluid temperature. Hence we found an enhancement in the heat function and its later thickness as $A^{*}, B^{*}$ improves. 


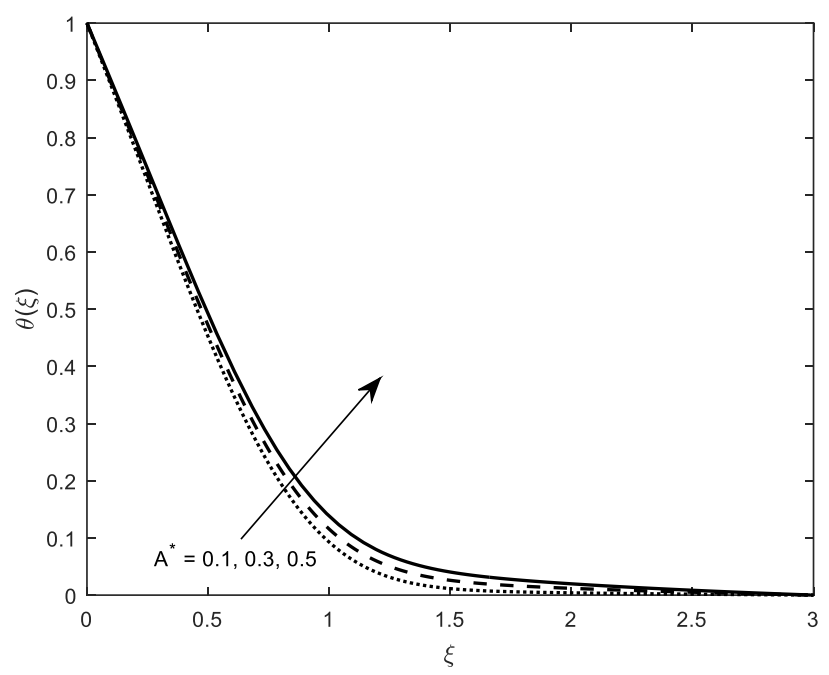

Figure 4. Influence of $A^{*}$ on the curves of temperature.

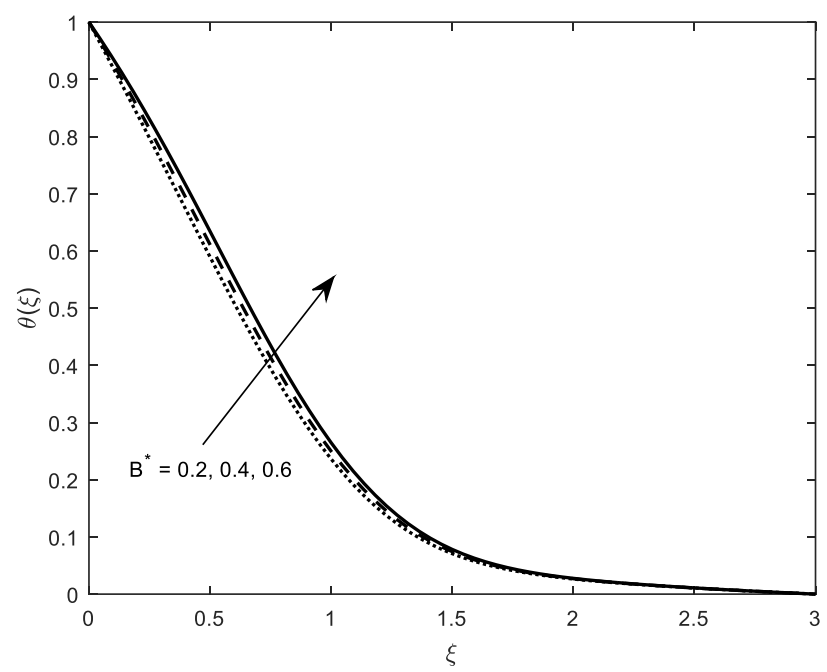

Figure 5. Influence of $B^{*}$ on the curves of temperature.

Figures 6 and 7 render the curves of velocity and heat functions for ascending values of Powell-Eyring liquid parameter $(\varepsilon)$. From Figure 6 we spot that heightening the values of $\varepsilon$ diminishes the curves of velocity function whereas from Figure 7 we may clinched that superior values of $\varepsilon$ magnifies the temperature fields. Mostly, higher values of $\varepsilon$ develops friction near the flow surface. Due to this friction, we noticed the results of that kind. 


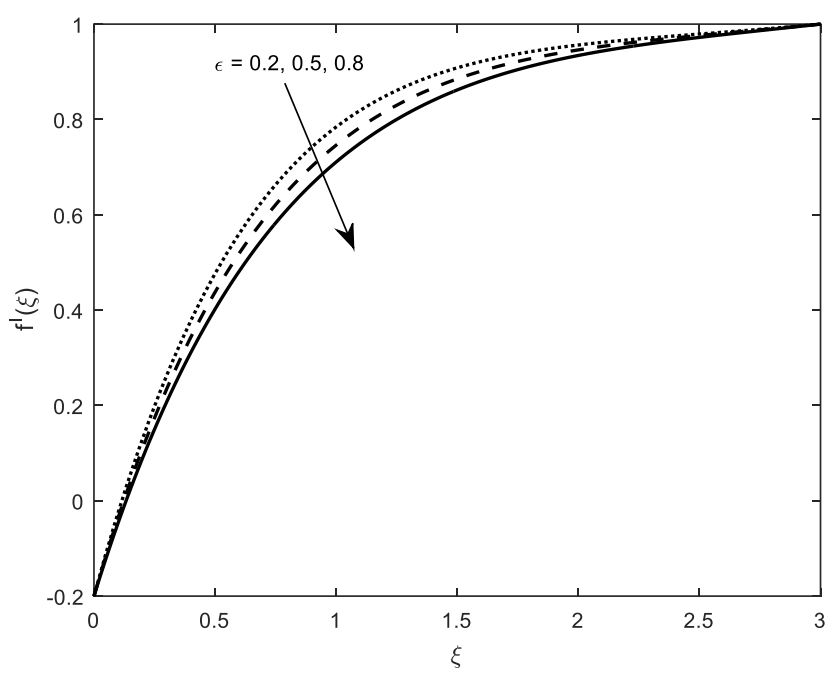

Figure 6. Influence of $\varepsilon$ on the curves of velocity.

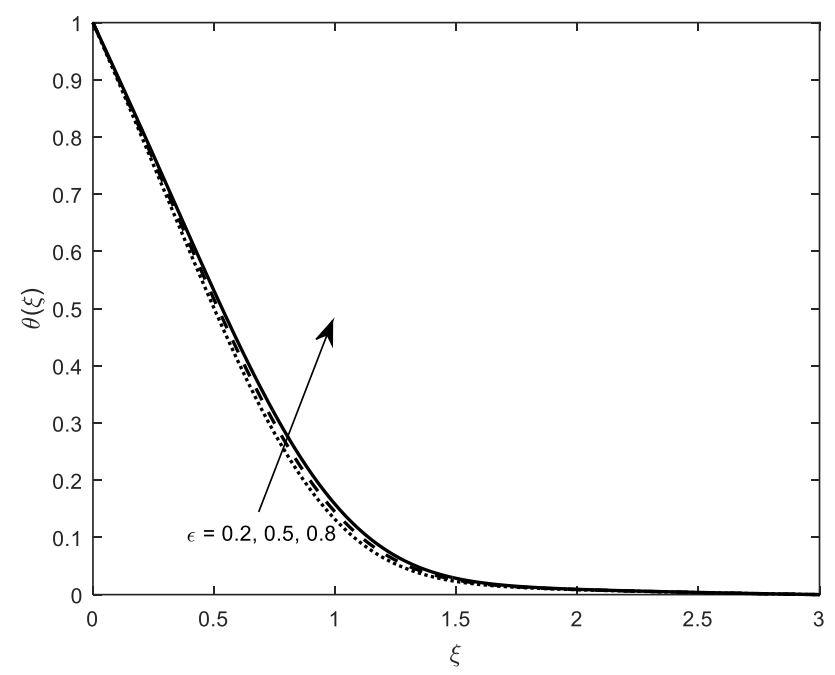

Figure 7. Influence of $\varepsilon$ on the curves of velocity temperature.

Figure 8 is sketched to analyze the essence of the constant of moving parameter $\lambda$ on velocity distribution. We detected that there is a contra relation between the velocity and $\lambda$. So the velocity function and its layer thickness destroy with swelling values of constant of moving constraint. The influence of mixed convection parameter on the curves of heat function is portrayed in Figure 9. It is found that raising values of $\Gamma$ suppresses the distribution of temperature. Also, the measure of thermal transport increase due to high gravitational force caused by the increase of mixed convection parameter $\Gamma$. The inspiration of $\operatorname{Pr}$ on $\theta(\xi)$ is depicted in Figure 10. The figure enables us to notice that an enhancement in Pr lessens the distribution of heat. Actually, an upsurge in Prandtl number decreases the thermal conductivity. Due to this reason, fluid temperature and the corresponding layer thickness diminishes. Figure 11 is outlined to know the behavior of $R d$ on the distribution of heat function. It is discerned that an intensification in $R d$ enhances the fluid temperature. 
Hence we notice uplift in the heat function and its later thickness for higher radiation parameter.

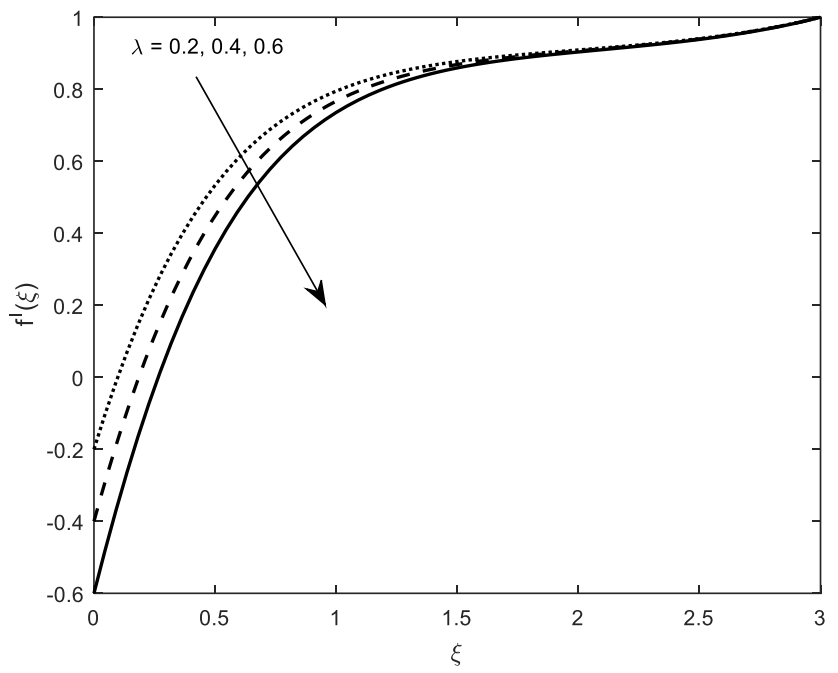

Figure 8. Influence of $\lambda$ on the curves of velocity.

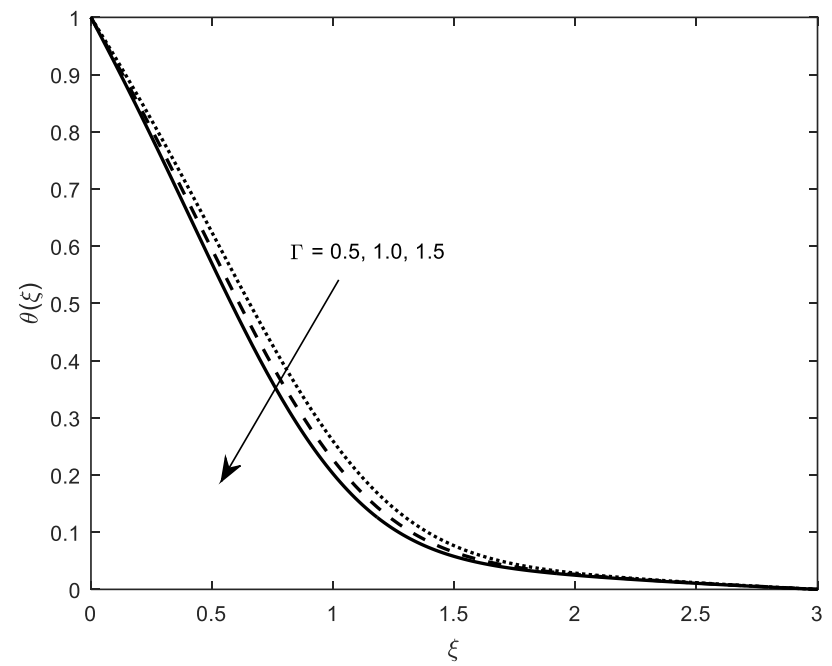

Figure 9. Influence of $\Gamma$ on the curves of temperature. 


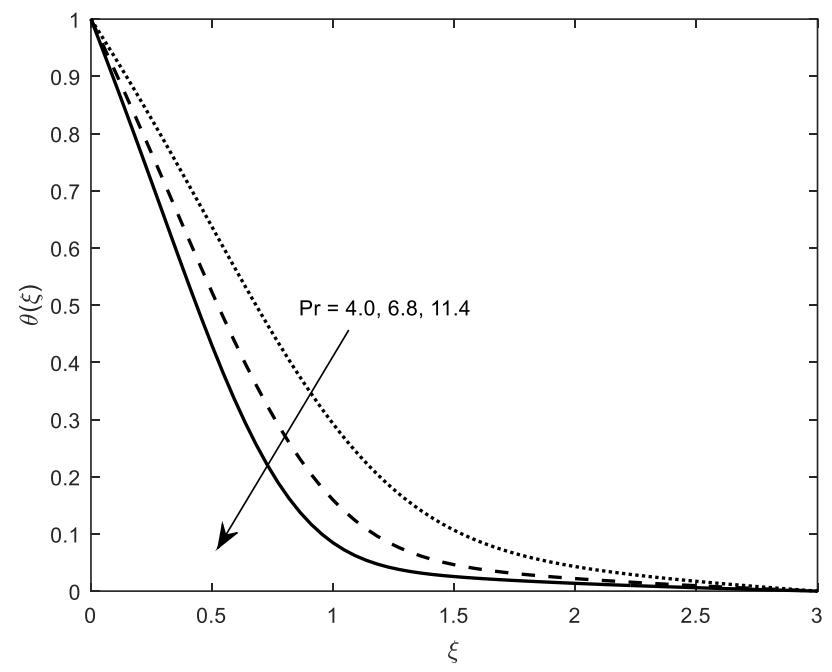

Figure 10. Influence of Pr on the curves of temperature.

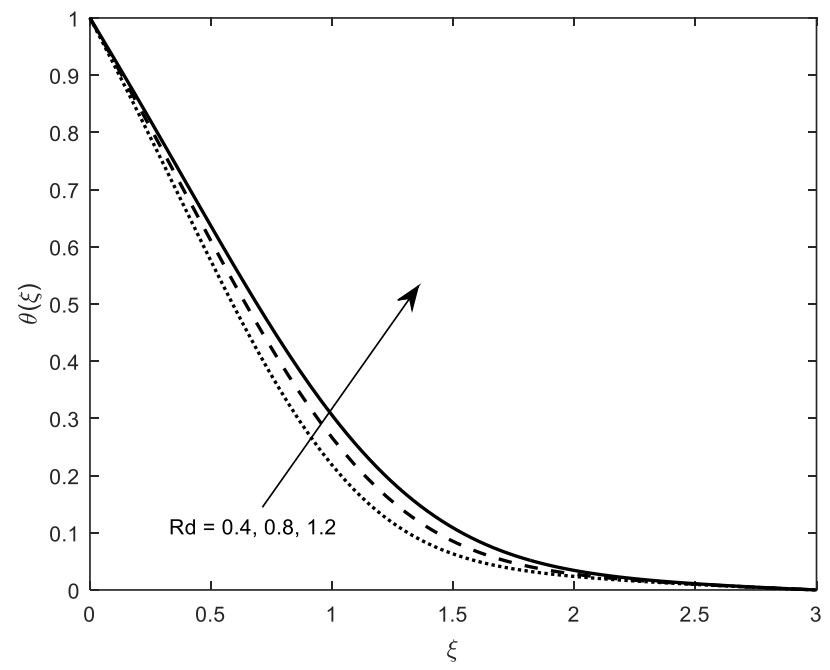

Figure 11. Influence of $R d$ on the curves of temperature.

The influence of sundry physical parameters such as magnetic field parameter, variable heat sink or source parameters, buoyancy parameter, Powell-Eyring fluid parameter, constant of moving parameter, radiation parameter and Prandtl number on $f^{\prime \prime}(0)$ and $\theta^{\prime}(0)$ is examined through Table 2. It is found that rising values of $A^{*}, B^{*}, \lambda$ and $R d$ decreases the measure of thermal transport but a conflicting consequence is noticed for friction factor. Boosting values of $M$ and $\varepsilon$ lessens both the measure of thermal transport and friction factor. A strength in buoyancy parameter $(\Gamma)$ causes an improvement in both the $f^{\prime \prime}(0)$ and $\theta^{\prime}(0)$. Heat transfer rate enhances with rising values of $\operatorname{Pr}$ but a reverse trend is noticed in friction factor. 
Table 2. Impact of numerous parameters of the problem on skin friction coefficient $\left(f^{\prime \prime}(0)\right)$ and the rate of heat transport $\left(-\theta^{\prime}(0)\right)$.

\begin{tabular}{|c|c|c|c|c|c|c|c|c|c|}
\hline$M$ & $A^{*}$ & $B^{*}$ & $\varepsilon$ & $\operatorname{Pr}$ & $\Gamma$ & $\lambda$ & $R d$ & $f^{\prime \prime}(0)$ & $-\theta^{\prime}(0)$ \\
\hline 1.0 & & & & & & & & 1.5510 & 1.3808 \\
\hline 2.0 & & & & & & & & 1.4818 & 1.3643 \\
\hline 3.0 & & & & & & & & 1.4164 & 1.3482 \\
\hline & 0.1 & & & & & & & 1.3203 & 0.8525 \\
\hline & 0.3 & & & & & & & 1.3226 & 0.8200 \\
\hline & 0.5 & & & & & & & 1.3249 & 0.7873 \\
\hline & & 0.2 & & & & & & 1.8031 & 0.7966 \\
\hline & & 0.4 & & & & & & 1.8064 & 0.7098 \\
\hline & & 0.6 & & & & & & 1.8099 & 0.6186 \\
\hline & & & 0.2 & & & & & 1.8719 & 0.9784 \\
\hline & & & 0.5 & & & & & 1.7673 & 0.9443 \\
\hline & & & 0.8 & & & & & 1.6476 & 0.9109 \\
\hline & & & & 4.0 & & & & 2.2206 & 0.6657 \\
\hline & & & & 6.8 & & & & 2.2003 & 0.9028 \\
\hline & & & & 11.4 & & & & 2.1854 & 1.0989 \\
\hline & & & & & 0.5 & & & 1.3483 & 0.6836 \\
\hline & & & & & 1.0 & & & 1.5913 & 0.7467 \\
\hline & & & & & 1.5 & & & 1.8223 & 0.8003 \\
\hline & & & & & & 0.2 & & 2.2003 & 0.9028 \\
\hline & & & & & & 0.4 & & 2.4625 & 0.7295 \\
\hline & & & & & & 0.6 & & 2.6715 & 0.5538 \\
\hline & & & & & & & 0.4 & 2.2091 & 0.8141 \\
\hline & & & & & & & 0.8 & 2.2155 & 0.7520 \\
\hline & & & & & & & 1.2 & 2.2205 & 0.7051 \\
\hline
\end{tabular}




\section{CONCLUSIONS}

This study is focused on describing the features of heat transport of Eyring-Powell liquid flow past a shrinking wedge. The impact of radiative heat flux and uneven heat sink/source is also accounted. The main conclusions of the investigation are listed below.

- $\quad$ For increase in irregular heat parameters the distribution of temperature increases. Also, they did not show any impact on friction factor.

- $\quad$ The velocity function has a converse relationship with, shrinking, magnetic field and material fluid parameter.

- Temperature has an inverse relationship with Prandtl number, mixed convection parameter.

- It is motivating to note that increasing values of either mixed convection parameter or shrinking parameter hikes the friction near the surface.

- $\quad$ Fluid temperature is an swelling function of $M, \varepsilon$ and $R d$.

- A tremendous development in heat transfer is perceived with a hike in $\Gamma$ or $\operatorname{Pr}$.

\section{ACKNOWLEDGEMENTS}

The authors would like to thank the Sri Venkateswara University for providing research facilities. Also thank the reviews for their valuable suggestions for the enhancement of the article.

\section{NOMNECLATURE}

$\begin{array}{ll}a, c & \text { Constants } \\ B & \text { magnetic field } \\ B_{0} & \text { varying magnetic field } \\ C_{f} & \text { friction factor } \\ c_{p} & \text { specific heat } \\ d & \text { Constant } \\ g & \text { gravitational force } \\ k & \text { thermal conductivity } \\ k^{*} & \text { mean absorption coefficient } \\ M & \text { magnetic field parameter } \\ m & \text { power index parameter } \\ N u_{x} & \text { Nusselt number } \\ \mathrm{Pr} & \text { Prandtl number } \\ q_{r} & \text { radiative heat flux } \\ q_{w} & \text { surface heat flux } \\ R d & \text { radiation parameter } \\ \mathrm{Re}_{x} & \text { Reynold's number }\end{array}$

$W b$

$K g \cdot s^{-2} \cdot A^{-1}$

$J \cdot \mathrm{kg}^{-1} \cdot \mathrm{K}^{-1}$

$m \cdot s^{-2}$

$K g . m . s^{-3} \cdot K^{-1}$

-

-

$K g . s^{-3}$

W. $m^{-2}$ 


$\begin{array}{lll}T & \text { temperature of the fluid } & K \\ T_{w} & \text { temperature near the surface } & K \\ T_{\infty} & \text { ambient fluid temperature } & K \\ u, v & \text { velocity components in }(x, y) \text { directions } & m \cdot s^{-1} \\ u_{e} & \text { shrinking velocity } & m \cdot s^{-1} \\ u_{w} & \text { free stream velocity } & m \cdot s^{-1} \\ \beta & \text { Greek Symbols } & \\ v & \text { Powell-Eyring parameter } & - \\ \mu & \text { kinematic viscosity } & \mathrm{m}^{2} \cdot \mathrm{s}^{-1} \\ \sigma & \text { dynamic viscosity } & \mathrm{Kg}^{-1} \cdot \mathrm{m}^{-1} \\ \sigma^{*} & \text { electrical conductivity } & \mathrm{Kg}^{-1} \cdot \mathrm{m}^{-3} \cdot \mathrm{s}^{3} \cdot \mathrm{A}^{2} \\ \beta_{T} & \text { Stefan-Boltzman constant } & \mathrm{W} \cdot \mathrm{m}^{-2} \cdot \mathrm{K}^{-4} \\ \varepsilon, \delta & \text { thermal expansion coefficient } & \mathrm{K}^{-1} \\ \rho & \text { material fluid parameters } & - \\ \tau_{w} & \text { density of the fluid } & \mathrm{Kg} \cdot \mathrm{m}^{-3} \\ \Gamma & \text { surface shear stress } & \\ \lambda & \text { convection parameter } & \\ \xi & \text { constant of moving parameter } & \\ \eta & \text { similarity variable } & \end{array}$

\section{REFERENCES}

[1] Chamkha AJ, Takhar HS, Beg OA. Radiadive free convective non-Newtonian fluid flow past a wedge embedded in a porous medium. International Journal of Fluid Mechanics Research 2004;31:101-115.

[2] Eldaheb EMA, Salem AM. Hall effects on MHD free convective flow of nonNewtonian power law fluid over at a stretching surface. International Communications in Heat and Mass Transfer 2004;31:343-354.

[3] Hsiao KL. MHD mixed convection for viscoelastic fluid past a wedge. International Journal of Non-Linear Mechanics 2011;46:1-8.

[4] Surati HC, Timol MG. Numerical study of forced convection wedge flow of some non-Newtonian fluids. International Journal of Applied Mathematics and Mechanics 2012;6:50-65.

[5] Kumar KA, Reddy JVR, Sugunamma V, Sandeep N. Impact of frictional heating on MHD radiative ferrofluid past a convective shrinking surface. Defect and Diffusion Forum 2017;378:157-174.

[6] Postenlicu A, Pop I. Falkner-Skan boundary layer flow of a Power-law fluid past a stretching wedge. Applied Mathematics and Computation 2011;217: 4359-4368. 
[7] Kuamr KA, Sugunamma V, Sandeep N. Numerical exploration of MHD radiative micropolar liquid flow driven by stretching sheet with primary slip: a comparative study, Journal of Non-Equilibrium Thermodynmics 2018; DOI: 10.1515/jnet-20180069.

[8] Ramadevi B, Sugunamma V, Kumar KA, Reddy JVR. MHD flow of Carreau fluid over a variable thickness melting surface subject to Cattaneo-Christov heat flux, Multidiscipline Modeling in Materials and Structures 2019; 15:2-25.

[9] Kuamr KA, Sugunamma V, Sandeep N. Impact of non-linear radiation on MHD nonaligned stagnation point flow of micropolar fluid over a convective surface, Journal of Non-Equilibrium Thermodynamics 2018;43:327-345.

[10] Khan MS, Karim I, Islam MS, Wahiduzzaman M. MHD boundary layer radiative, heat generating and chemical reacting flow past a wedge moving in a nanofluid. Nano Convergence. 2014; DOI:10.1186./s40580-014-0020-8.

[11] Awaludin IS, Ishak A, Pop I. On the stability of MHD boundary layer flow over a stretching/shrinking wedge. Scientific Reports 2018;8: DOI:10.1038/s41598-01831777-9.

[12] Kuamr KA, Reddy JVR, Sugunamma V, Sandeep N. Magnetohydrodynamic Cattaneo-Christov flow past a cone and a wedge with variable heat source/sink. Alexandria Engineering Journal 2018; 57: 435-443.

[13] Khan A, Pop I. Boundary layer flow past a wedge moving in a nanofluid. Mathematical Problems in Engineering 2013, Article Id: 637285.

[14] Kumar KA, Ramadevi B, Sugunamma V. Impact of Lorentz force on unsteady bio convective flow of Carreau fluid across a variable thickness sheet with non-Fourier heat flux model, Defect and Diffusion Forum 2018;387:474-497.

[15] Kumar KA, Sugunamma V, Sandeep N, Reddy JVR. Impact of Brownian Motion And Thermophoresis on Bioconvective Flow of Nanoliquids Past a Variable Thickness Surface With Slip Effects, Multidiscipline Modeling in Materials and Structures 2018;15: 103-132.

[16] Rashidi MM, Rostami B, Freidoonimehr N, Abbasbandy S. Free convective heat and mass transfer for MHD fluid flow over a permeable vertical stretching sheet in the presence of radiation and buoyancy effects. Ain Shams Engineering Journal 2014;5:901-912.

[17] Kandasamy R, Muhaimin I, Khamis AB. Thermophoresis and variable viscosity effects on MHD mixed convective heat and mass transfer past a porous wedge in the presence of chemical reaction. Heat and Mass Transfer 2009;45:703-712.

[18] Hayat T, Asad S, Mustafa M, Alsaedi A. Radiation effects on the flow of PowellEyring fluid past an unsteady stretching sheet with non-uniform heat source/sink. Plos One. 2014;9:https://doi.org/10.1371/journal.pone.0103214.

[19] Mutlag AA, Uddin MJ, Ismail AIM. Effect of thermal slip on the Falkner-Skan stretching and shrinking wedge flow of a Power-law fluid and heat transfer. Modern Applied Science 2013;7:57-69.

[20] Pal D. Combined effects of non-uniform heat source/sink and thermal radiation on heat transfer over an unsteady stretching permeable surface. Communications in Nonlinear Science and Nmerical Simulation 2011;16:1890-1904.

[21] Khan U, Ahmed N, Din STM. Influence of viscous dissipation and Joule heating on MHD bio-convection flow over a porous wedge in the presence of nanoparticles and 
gyrotactic microorganisms. Springer plus. 2016;5:DOI: 10.1186/s40064-016-37188.

[22] Reddy JVR, Sugunamma V, Sandeep N, Kumar KA. Influence of non-uniform heat source/sink on MHD nanofluid flow past a slendering stretching sheet with slip effects. Global Journal of Pure and Applied Mathematics 2016;12: 247-254.

[23] Kumar KA, Reddy JVR, Sugunamma V, Sandeep N. Simultaneous solutions for mhd flow of Williamson fluid over a curved sheet with non-uniform heat source/sink. Heat Transf. Res. 2018: DOI: 10.1615/HeatTransRes.2018025939.

[24] Kumar KA, Reddy JVR, Sugunamma V, Sandeep N. MHD flow of chemically reacting Williamson fluid over a curved/flat surface with variable heat source/sink. International Journal of Fluid Mechanics Research.2019;DOI: 10.1615/InterJFluidMechRes.2018025940

[25] Sulochana C, Kumar GPA, Sandeep N. Effect of frictional heating on mixed convection flow of chemically reacting radiative Casson nanofluid over an inclined porous plate. Alexandria Engineering Journal 2018;57:2573-2584.

[26] Yacob NA, Ishak A, Pop I. Falkner-Skan problem for a static or moving wedge in nanofluids. International Journal of Thermal Sciences 2011;50:133-139.

[27] Rana GC, Thakur, RC. Effect of suspended particles on thermal convection in RivlinEricksen fluid in a Darcy-Brinkman porous medium. Journal of Mechanical Engineering and Sciences 2012;2:162-171.

[28] Banyal AS, Sharma DK. On thermal convection of Rivlin-Ericksen fluid in the presence of vertical rotation. Journal of Mechanical Engineering and Sciences 2013;4:462-471.

[29] Muthucumaraswamy R, Radhakrishnan, M. Chemical reaction effects on flow past an accelerated vertical plate with variable temperature and mass diffusion in the presence of magnetic field, Journal of Mechanical Engineering and Sciences 2012;3:251-260.

[30] Muthucumaraswamy R, Dhanasekar N, Prasad, GE. Mass transfer effects on accelerated vertical plate in a rotating fluid with first order chemical reaction. Journal of Mechanical Engineering and Sciences 2013;3:346-355.

[31] Yih KA. Uniform suction/blowing effect on forced convection about a wedge: uniform heat flux. Acta Mechanica 199;128:173-181.

[32] Amstrong AN, Muthucumaraswamy R. MHD flow past a parabolic started vertical plate with variable temperature and mass diffusion. Journal of Mechanical Engineering and Sciences 2014;7:1251-1260. 